\title{
THE RUNGUS LONGHOUSE OF SABAH, MALAYSIAN BORNEO - A DYING ARCHITECTURE
}

\author{
Azizi Bahauddin, Aldrin Abdullah \& Nor Zarifah Maliki \\ School of Housing, Building and Planning \\ Universiti Sains Malaysia
}

\begin{abstract}
The Rungus tribal group can be found in the northeast corner of Sabah, Malaysian Borneo, farming the land mostly on agricultural products in small scale plantations. Their longhouses, facing extinction, are dual-purpose dwellings, constructed entirely of traditional materials utilising small split timbers lashed with rattan for the frame, palm fronds for the thatched roof, split bamboo for the floor and tree bark of hewn wood for the compartment walls. Each family has its own separate quarters off a common hall for socialising and community work. Village life is usually communal and the village is the major political unit based on the cultural traditions. Strongly related to the spirit of the place, the 'rice spirit', in particular, figures prominently in the Rungus people's beliefs and practices in controlling the spirits and the people's daily life. Unfortunately, all of these unique beliefs seem to have disappeared through time, thus requiring proper documentation of the longhouses. The objectives gear towards analysing the architectural values and investigating cultural understanding associated with the longhouses. Most importantly, the issue of how the Rungus people relate to the environment is studied through the tangible and intangible cultural aspects of the people. The research utilises the observation technique, interviews with the residents, visual data collection and measured drawings of five longhouses as the processes to document data. The paper instigates an investigation into the conformity of the Rungus people of their place in the environment to perpetuate their lifestyle in a land that is surrounded by nature.
\end{abstract}

Keywords: Rungus people, longhouse, communal, spirit, environment

\section{INTRODUCTION}

The indigenous people of Sabah and Sarawak are synonymous with their longhouse architecture. Unfortunately, the Rungus people of Kudat in the Bengkoka Peninsula, the sub-group of the Kadazan-Dusun (Hans, 2008), with their longhouse design are not receiving attention. In theory, the longhouses have long existed as a mode of rural settlement, particularly among the indigenous peoples of Sabah and Sarawak (Ong, 2005). However, Malaysians in general have a vague conception of Rungus culture as well as the architectural language of this longhouse as a housing pattern, with clearcut boundaries of public and private spaces for the domestic families dwelling in these longhouses. This is due to the lack of research being done about this community and its architecture. To further aggravate the situation of lack of information, the Rungus community has been relocated to their new settlements away from their ancestral land (Appell, 1983). The original landscape of the Rungus people in Kudat includes puru, patches of forest approximately one hectare in size and inhabited by rogon (spirits) (Massey, et. al, 2011). But these areas are reducing in size. The problem indicates that the people are also losing their architectural heritage through the relocation of their settlements.

The Rungus people of Kudat are a sub-group of Kadazan-Dusun, Sabah's major indigenous people on the island of Malaysian Borneo (figure 1\& figure 2). Troubled by the relocation of settlements, this people are losing their strong foothold in their traditional land tenure where each village held rights as a corporate entity over its territory. The villages had clear boundaries and only members of it could 
harvest their cultivated open lands in this territory annually. Once the last crops were removed, the areas were given back to the control of the village and could be used again by anyone in the village in a system called 'circulating usufruct' (the right to enjoy benefits) (Appell, 1983). However, the right is slowly stripped away hence the loss of their communal architectural heritage with less than ten houses remaining.

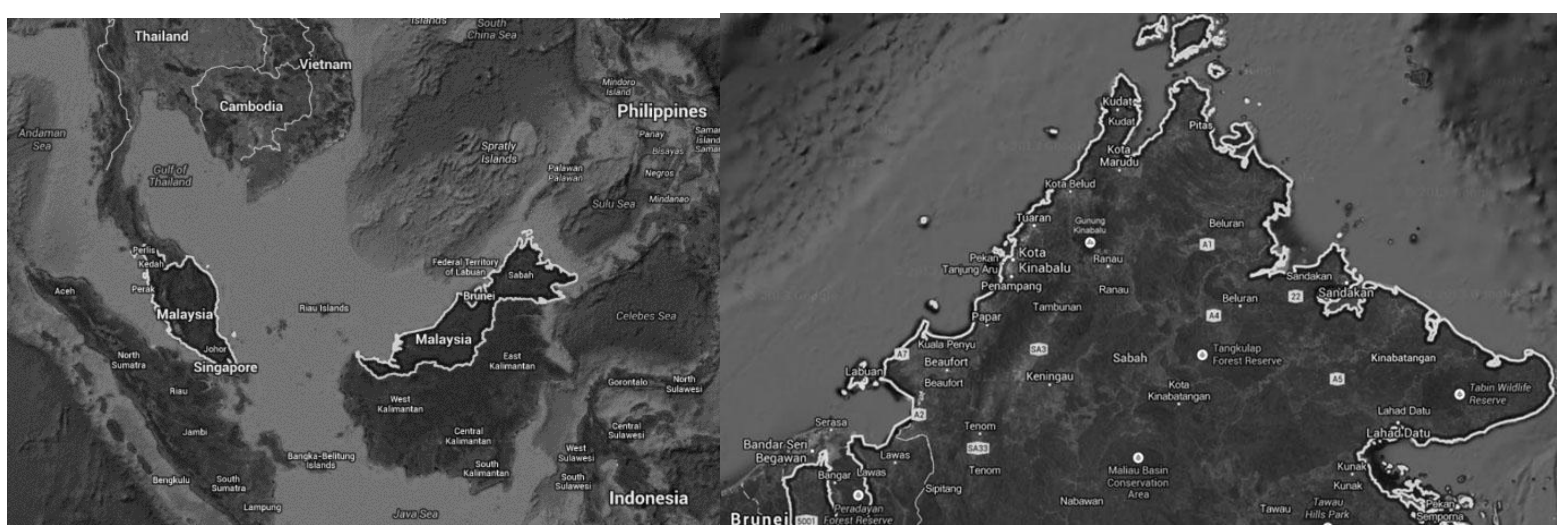

Figure 1 - Map of Sabah on the

Figure 2 - Map of Sabah

Malaysian Borneo Island

Culturally, the house is the embodiment of the community reflecting all communal rules and customs. The research aims:

a. To investigate the architectural and cultural aspects of a communal dwelling of the Rungus longhouse

b. To examine the cultural influences that dictate the communal space planning of the Rungus longhouse and its environment

c. To establish an architectural language between the philosophy of the detail embellishments and the Rungus longhouse for design understanding

There is no current exploratory research being done in understanding the Rungus longhouse in relation to its communal dwelling. This can be done by studying the traditional philosophy of the Rungus people. This research embarks into an unchartered territory that can be perceived as a new angle of studying a longhouse design setting in relation to communal dwelling. This investigations delves into the meaning of Rungus culture in order to understand the architecture of the longhouse by employing a few steps as research method.

\section{METHODOLOGY}

The research employs a qualitative method relying on ethnography and phenomenology documentation supported by an in-depth investigation in the Rungus villages within Kudat vicinity (figure 3). It will be supported by architectural detail studies on the longhouse, interviews, naturalistic observation and visual data collection. Ultimately, the expected outcomes include the understanding of the architectural and cultural aspects of the Rungus longhouse (figure 4) in relation to communal space planning and activities. However, the lack of secondary data requires the researcher to depend on and source out from primary sources. Since this research is focussing on the Rungus cultural interpretation of traditional philosophy of a communal dwelling in a longhouse design context, it is imperative that the study reviews the Rungus customs and understanding of Rungus longhouse. It is known that any culture in the world has a ritual that is related to practices of spiritual, mental and physical well-being associated with their life styles. 


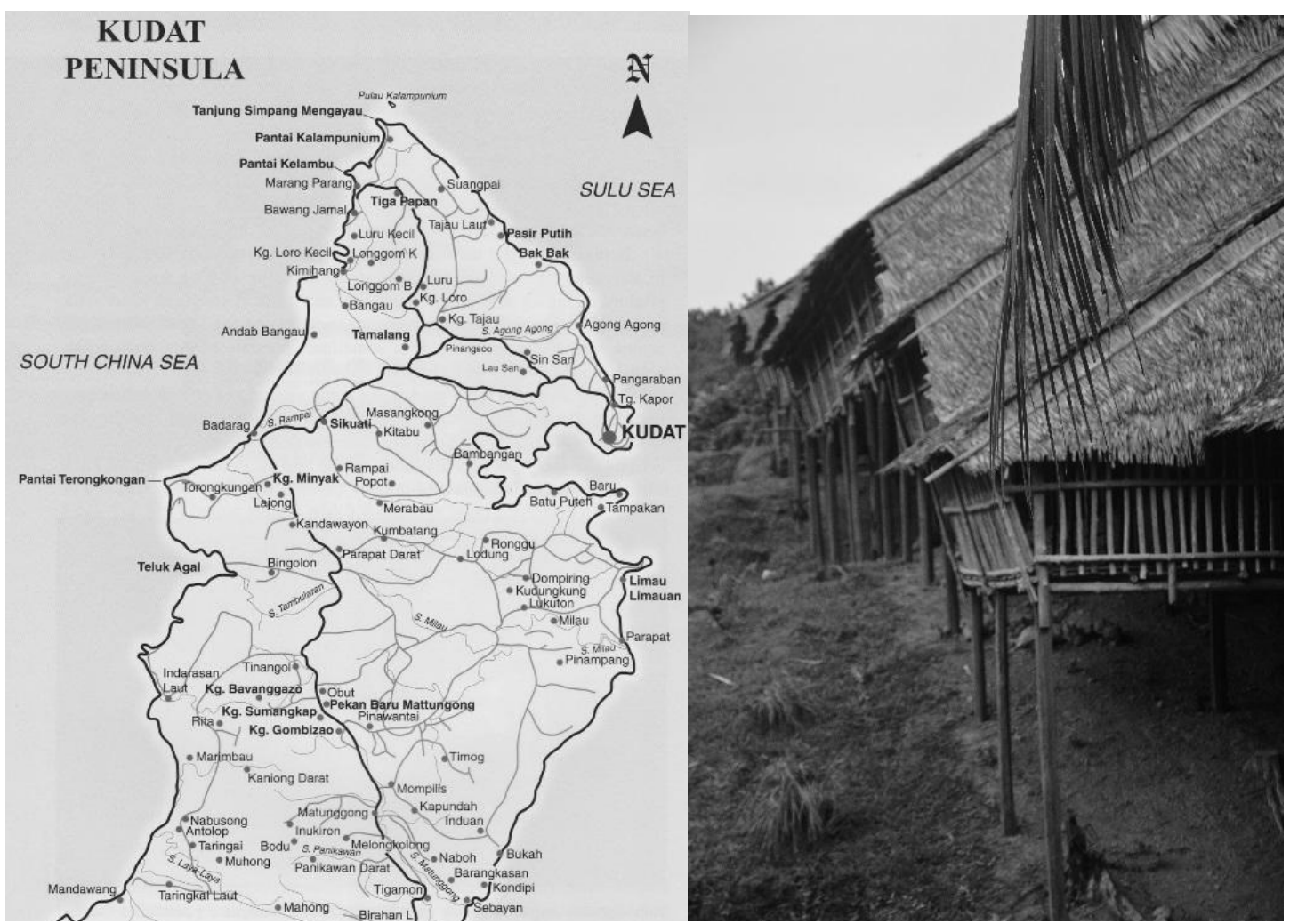

Figure 3 - May of Kudat and vicinity

Source: Huton, 2003

Figure 4 - Rungus longhouse

The longhouses chosen are the houses that have the most original form of Rungus longhouse features. A pilot study identifies specific longhouses before further work can take place. This process involves the phenomenology method looking at the evolution of the longhouse and what influences warrant changes in the longhouse design. However, for this paper there is only one case study investigated. It is based on the Maranjak longhousein the District of Kudat, Sabah. This research method also involved some non-structured interview of the owners of the longhouse. This process ran simultaneously with the visual data collection. These steps focus on the residents and their perception of the detail Rungus longhouse space planning while from the experts the interview will focus on types and customs, rituals and philosophy associated with the Rungus cultural system. This method is also looking into the tribal leaders' knowledge on the Rungus longhouse, be it associated with any cultural philosophy or traditional customs. Most important of all is the established connection between the traditions and the well-being of the house and how it stands.

\section{THE RUNGUS COMMUNITY}

This paper is examining the longhouse of the Rungus people in an area famed for the title 'The Tip of Borneo, along the northern coastal line of Sabah. Though it is uncertain how long the Rungus have been occupying the area, they are considered to be the most traditional tribe in Sabah due to their isolation from the bigger towns for so many years. While many have adapted to modern living rather well, the older generations still clutch to their unique culture and traditions (Heaven at the Edge of Borneo, 2012). The Rungus longhouse is singled out for this research for the reason that the Rungus community has lived, or are still living, in these longhouses. The longhouse embodies a communal house design made up of individual spaces. This interrelationship concept is very valuable to the understanding of the longhouse design. On the other hand, the Rungus longhouse has also been targeted as one of the major tourism attractions in Sabah that contribute to the construction of the improvised version of the Rungus longhouse, a detachment from the authentic form of the structure. 
Non-Rungus people perceive the Rungus longhouse as a communal dwelling where its occupants share a big house. The villagers are mainly farmers and many of its women are quite renowned in their handicraft making skills. They display a very close knit bond among the people where communal activities demonstrate the involvement of every person in the community (PengiranBagul, 2005). The domestic family's economy is based on (1) the swiddenor slash and burnis a system in agriculture where lands are cultivated until its fertility diminishes, then it is abandoned until is restored naturally in the cultivation of rice, maize, cassava, and a variety of vegetables; (2) the raising of pigs, chickens, and frequently water buffalo; (3) the planting and cultivation of a large variety of fruit trees; and (4) the sale of domestic manufactures. The most important of these are clothing of various types that are woven exclusively by women from cotton they have grown, spun into thread, and dyed (Appell\&Appell, 2003; Anonymous, 2009). These activities are also the governing factors in the design direction of the longhouse along with their cultural beliefs and communal activities.

The Rungus in the north of Sabah (Kudat area) are arguably the most traditional ethnic group here. They remain remarkably strong in this time of transition, and keep up with an age-old life-style. Their life, as that of most tribes in Borneo, revolves around rice: the preparing of the rice field, or the clearance of a hill plot, the growing of rice and looking after it, and finally the harvest. Large coconut and banana groves enable the Rungus to earn cash, but in all, their traditional life-style suits them very much and seems to keep them out of trouble and stress. The Rungus seem to have been the last Dusunic immigrants to Sabah to settle here permanently, long before the arrival of the British. They have up to-date conserved much of their cultural heritage. The Rungus are a sub-group of the Kadazan-Dusun, with a distinctive language and a few dialects, architecture, adat (customs), and outfit. Many people still, especially from the elder generation, dress the way they have attired when they were still unaffected by outside influences, and it is presumed that most of the other tribes of the KadazanDusun community had similar dress and attire: simple black sarongs for the women, wide black trousers for the men and beaded accessories.

\section{THE RUNGUS LONGHOUSE}

Considered one of the most traditional ethnic groups in Sabah, many Rungus live in longhouses, with each family having its own separate quarters off a common hall. At the edge of the communal hall, a well-ventilated platform of split bamboo with outward sloping walls provides a place for socializing and communal work. The Rungus longhouse is quite different from the Murut longhouse. The houses are not perched on high stilts, but are usually only three to five feet above ground (figure 5).

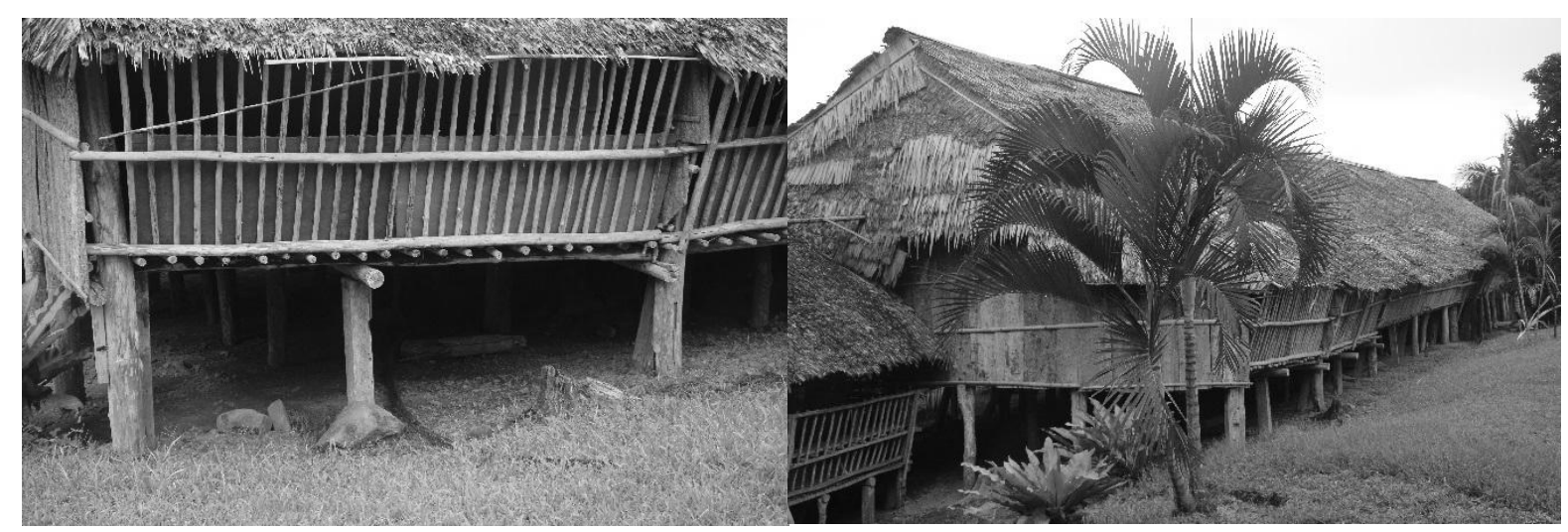

Figure 5 - The Rungus longhouse stilts Figure 6 - Sloped roof

Through observation, one can see that the roof is low, and the walls slope outward (figure 6). In olden times, longhouses of over 75 doors are said to have been common. Now, they rarely exceed 10 doors. Usually single storey, more modern two-storey versions of the longhouse also exist. Single- 
family houses are sometimes built near the longhouse - these take the same form, but are short.Dogs, chickens and other domesticated animals abound in the clearing where the houses stand, and children too young to help with the daily chores play in the sand in the clearing. According to an interview with one of the owners of the longhouse, the Rungus people being friendly and warm will quickly announce the arrival of a stranger, and whoever passes will be invited into the house for a rest. During the hot afternoons, a palpable laziness prevails in the houses. People doze on the platform in the gallery or work on some handicraft if they are not at work in the fields, or catch fish and crabs. When everybody comes back from work in the late afternoon, the general area bounces under the many feet.When the house gets alive in the late afternoon, the ladies will take out their work of basketry, string beads or weave sashes on back strap looms. It is not infrequent to see old ladies who have their wrists still encircled in brass coils with white and black shell-bracelets at either end, and wear the traditional home-woven sarong. They also wear antique heirloom beads, and the betel container is an old, finely worked Bruneian brass receptacle. Ladies who do wear traditional gear are often very much respected Bobohizans, the shamans of the Rungus. Besides traditional healing with natural herbs the Bobohizans are here to maintain harmony between humans, nature and astral world according to their age-old belief system. This is where customs and traditions play important roles in harmonising the existence of the house. But despite this peace and aspect of eternal sleepiness, the Rungus are far from being disconnected from the modern times. Cash-crops have allowed them already over the last 30 years to earn money, and in some cases wealth. The young people are being educated, some of them having gained university degrees and have entered the Sabah State Government (Herman, 2014).

\section{CASE STUDY - THE MARANJAK LONGHOUSE}

A few selected longhouses in the vicinity of Kudat District are the bases and locations for the pilot study and the field work. The few identified Rungus villages are Kampong Bavanggazo, Kampong Tinangol and Kampong Minyak,Kampong Hobut, Kampong Mompilis, Kampong Garib, Kampong Barangkason, Kampong Onduon, Kampong MombatuDarat, Kampong MombatuLaut, Kampong Nangka, Kampong Tinutudan, Kampong Kindangan, Kampong PanudahanJambu, Kampong Gombizau and Kampong Minikodong in the District of Kudat, Sabah. However, through first observation, many of the houses identified are no longer authentic. They have been through a lot of changes and only a few remaining can be considered authentic. One of the longhouses that still maintains the authenticity of the Rungus architecture is the Maranjak longhouse.

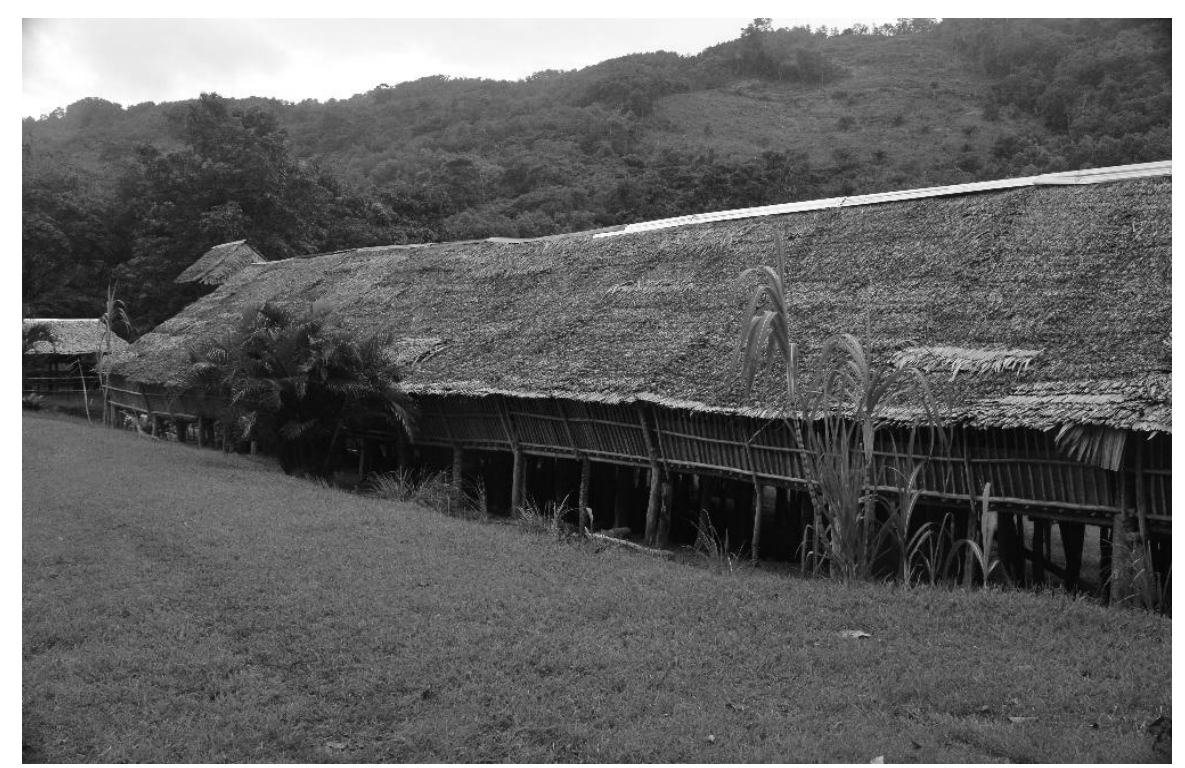

Figure 7 - The Maranjak longhouse 
The Maranjak longhouse (figure 7) is located in Kampong Bavangazo, Matunggonglocated about forty kilometres from Kudat. It now serves as a lodge and has a variety of functions and facilities for tourists such as accommodation and recreational activities.Visitors and locals alike will be able to identify a way oflife and traditional culture of old Rungus here as it also functions as a museum. Everything in the house is filled with heavy reflections of the local Rungus tribe's cultures and traditions. The buildings in the village are all built with the traditional materials used by people from the past in building their homes such as bamboos, and also palm leaves (for the roof). Although the society has stepped into the modern era, the Rungus tribe is still loyal towards their origins and thus, their homes are mostly built by using these traditional materials as a respect and remembrance of their elder generations.

\section{THE ARCHITECTURAL AND CULTURAL VALUES OF THE LONGHOUSE}

The Maranjak longhouse is a very long longhouse in dimension, extending to almost 100 metres long. This traditional Rungus longhouse utilises small split timbers lashed with rattan for the frame (figure 8), leaves for the thatched roof (figure 9), bamboo for the floor (figure 10) and tree bark for the compartment walls (figure 11). These materials are sought from the environment requiring rituals and community participation in erecting the house. This longhouse can accommodate more than twenty rooms and houses more than 100 people at one time. It is a house that caters for the communal needs by providing a communal space for meetings and areas for activities and functions (figure 12).

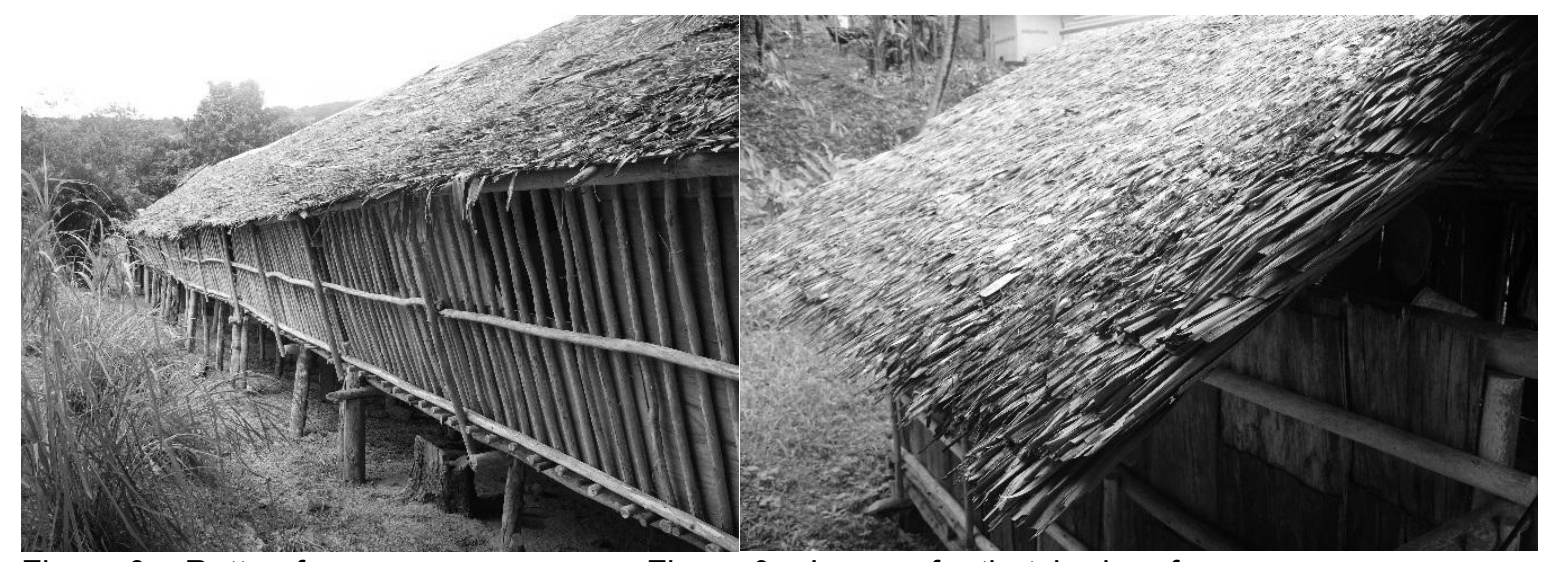

Figure 8 - Rattan frames

Figure 9 - Leaves for thatched roof

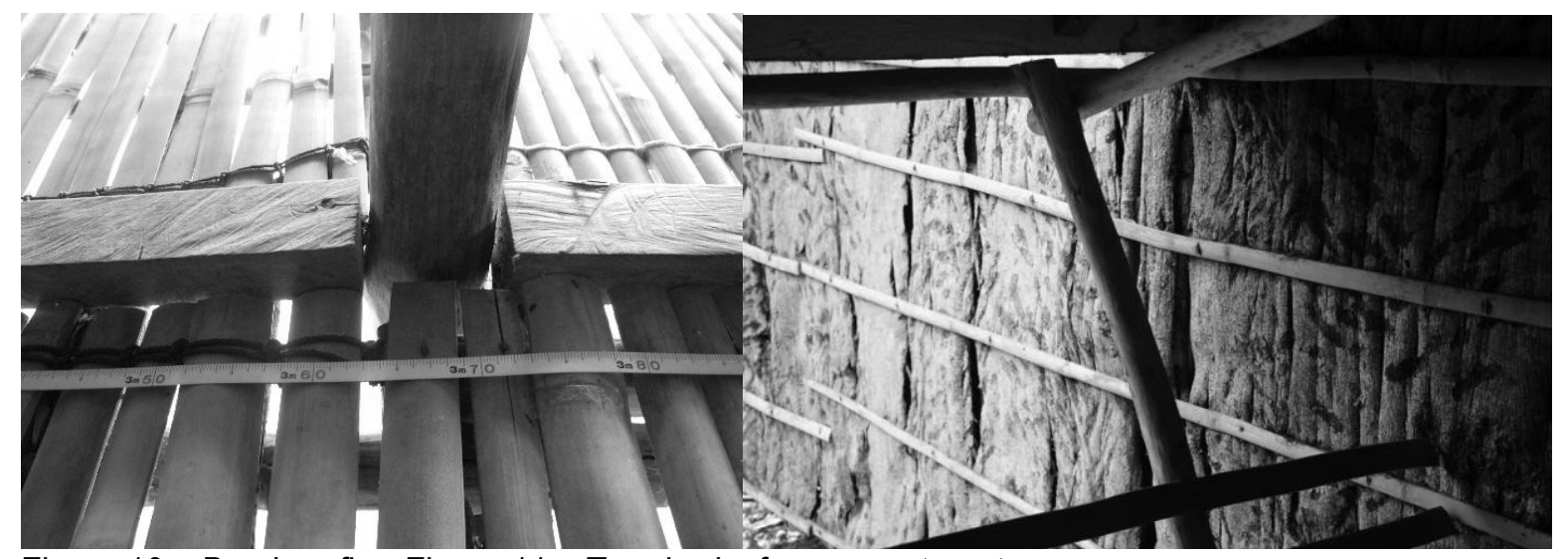

Figure 10 - Bamboo floorFigure 11 - Tree barks for compartment walls 


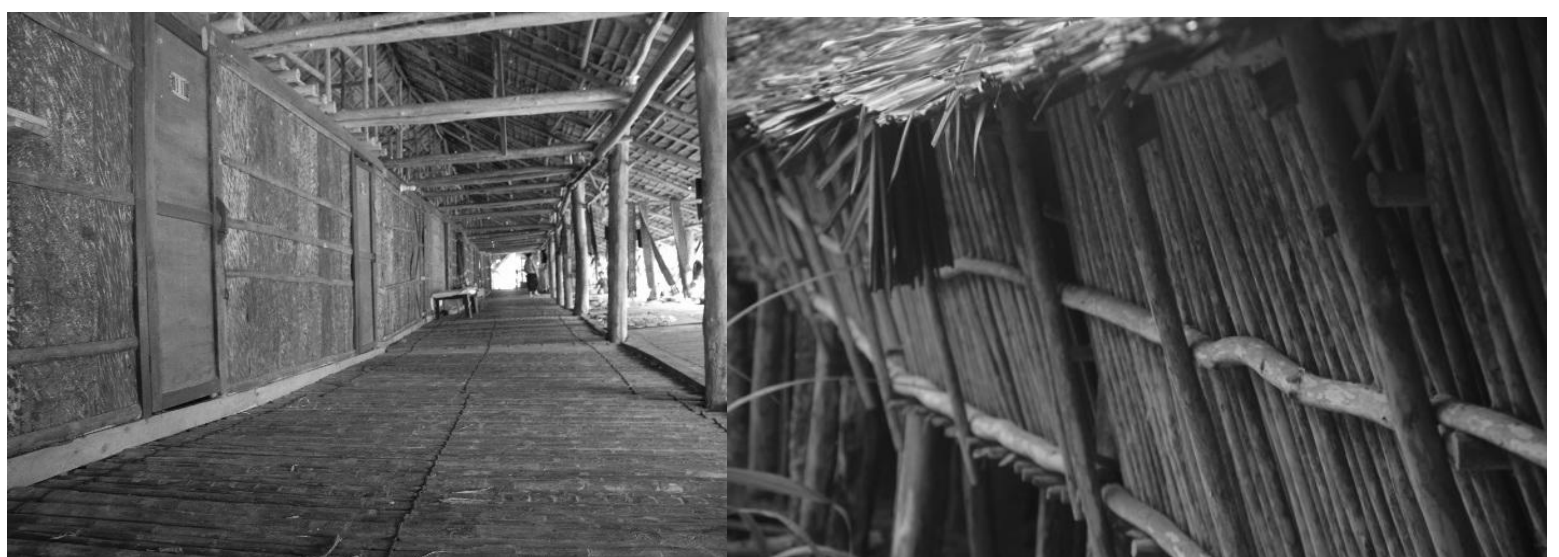

Figure 12 - Apadlansang

Figure 13 - Slanted side walls

(communal area)

The Rungus longhouse is designed in such a way that all daily activities can be done in the shade. Slanted side walls (figure 13) - an element synonymous with the traditional architecture of the Rungus people - allow occupants to sit comfortably without the need for modern or elaboratefurniture. This is especially important for the Rungus womenfolk who are renowned for their skills as bead weavers, and have to sit around all day with their legs stretched out to in order to produce their intricate handicrafts. One interesting architectural angle of the Rungus longhouse is that, regardless of the terrain, the occupants of the longhouse will always try to make the building as linear and as parallel as possible - which means an assortment of timber posts of all shapes and sizes propping up the single level floors of the longhouse, some of which may span up to 50-60 metres long. In fact, it was speculated that there once existed a Rungus longhouse in Kudat that had a span of 90 pintu or doors. Assuming that each door represented a single dwelling unit (approximately 3 metres in width), then this longhouse would have had been 270 metres long. Longhouses were usually built off the ground and along a terraced river bank. The longhouses were built on stilts for a number of reasons including to raise the building above the water should flooding occur, to allow the animals such as pigs, chickens and water buffalo to live underneath, too serve as a refuge or fortress in case of attack and to allow air to circulate throughout the house. One can see that the floor is made from split bamboo for practicality in terms of ventilation and the availability of the material. When one walked on it the floor was soft, spongy and one could feel the breeze come up from underneath. In fact, air circulated freely through the walls, roof and floors. It was cool and a slight breeze could be felt in all rooms. Hence, this architectural and cultural understanding of respecting nature's offerings has established an architectural language of the longhouse (Sokial, 2014). 
SHS Web of Conferences

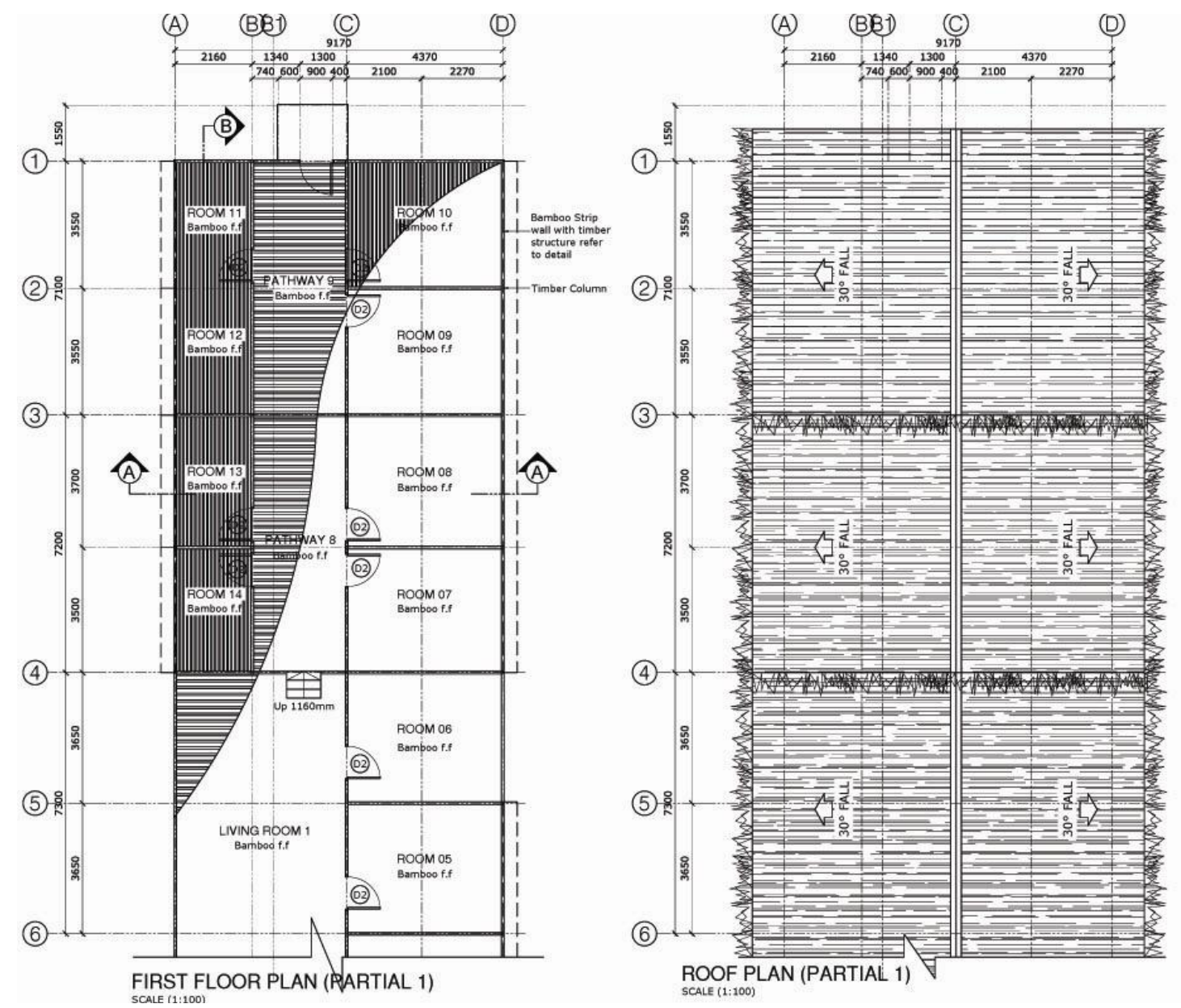

Figure 8 - Partial floor plan out of the 100 metres long

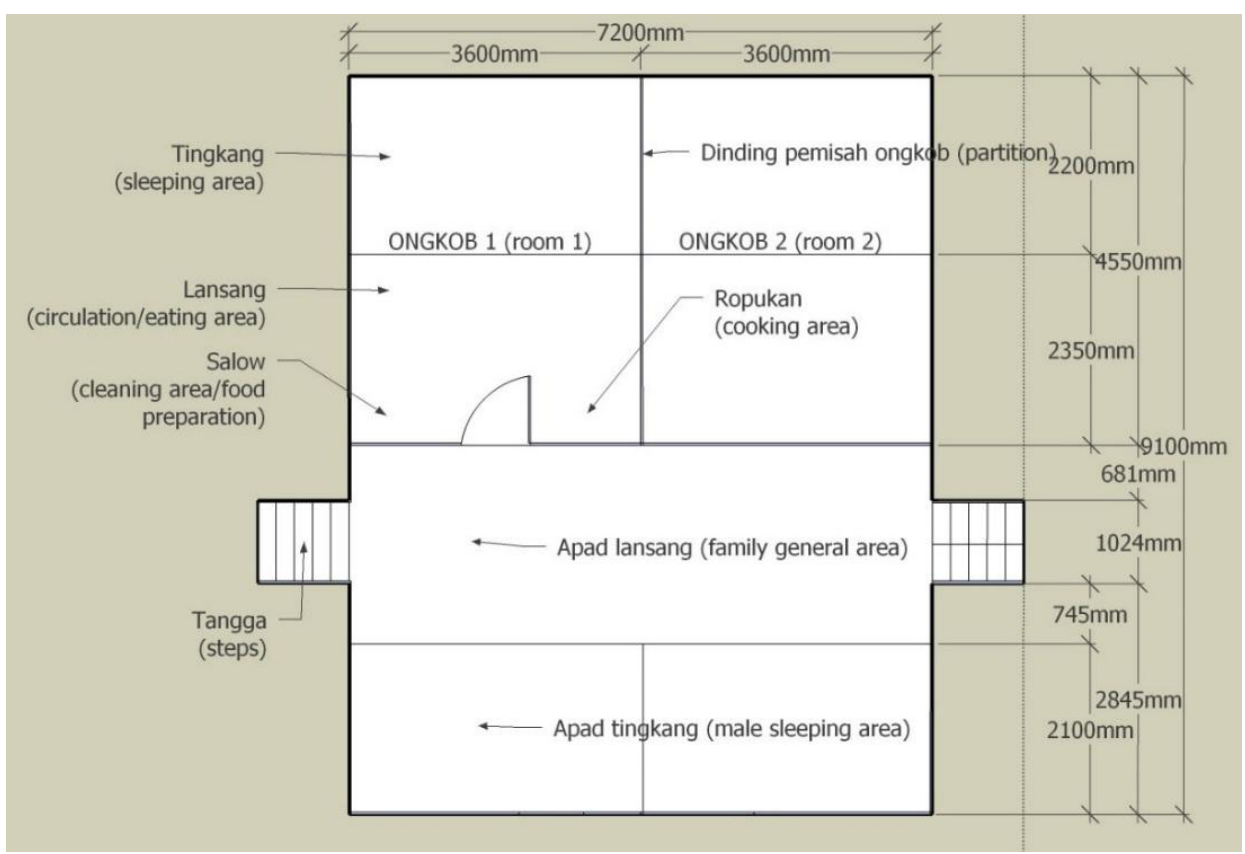

Figure 9 - Typical floor plan for ongkob(rooms) 


\section{CONCLUSION}

This paper examines and analyses the longhouse associated with the Rungus culture as the focus of the study. The research looks into the understanding of the longhouse and the meaning of Rungus cultural beliefs associated with the architecture. Among the Rungus there exists a vast inventory of poetry, prayers, songs, hymns related to bobohizanand word pictures of the life that they have led, their relation with the absolute and their relations with each other hence the creation of the longhouse to reflect the communal bond. This accumulation of oral literature, winnowed through the ages, is exquisite in its beauty and in its depth of wisdom. It provides a unique portrait of life as lived in a different time and place by individuals who share the human spirit. It encodes the basic cultural themes, values and propositions of this society, and it contains the creative voice of the people. This paper also analyses the Rungus cultural information in relation to communal dwelling of the Rungus longhouse. The research also establishes an architectural language derived from the architectural survey done on the longhouse. The merger between the meaning of the communal dwelling from the traditional Rungus point of definition and the architectural language understanding of the Rungus longhouse becomes a major determinant and contributor in this study. It encompasses issues of an architecture designed for communal activities that is steeped in tradition. The finding also includes the understanding of philosophy of Rungus and their interpretation in a contemporary language of architecture. As in the Rungus culture, the longhouse is defined in many aspects of life's activities imprinted with spiritual beliefs and religious teachings. Interpretation from the Rungus cultural point of view on its architecture has shown the meaning of this longhouse in depth and has in a way preserved some cultural and architectural knowledge of the Rungus longhouse despite its extinction.

\section{REFERENCES}

Anonymous. (1992). Head Hunting in Borneo. The Sea Dyaks and Other Races of Sarawak. Kementerian Pendidikan Malaysia. Kuala Lumpur: Dewan Bahasa danPustaka.

Anonymous. (2009). Penjelasan konsep Magahau berdasarkan keputusan Konvensyen Undangundang Adat Matunggong. Sabah Daily.

Appell, G. N. (2010). The Sabah Oral Literature Project. World Oral Literature Project: Cambridge.

Appell, G.N. (1983). Ethnic Groups in the Northeast Region of Indonesian Borneo and Their Social Organizations. Borneo Research Bulletin 15:38-45.

Appell, GN. (1995). Community Resources in Borneo: Failure of the Concept of Common Property and its Implications for the Conservation of Forest Resources and the Protection of Indigenous Land Rights. Yale Forestry and Environmental Studies Journal: 98, 32-56.

G. N. Appell, G.N. \&Appell L.W.R. (2003). Sabah Oral Literature Project: Death among The Rungus of Sabah, Malaysia: The Dissolution Of Personhood And Dispersion Of Multiple Souls And Spiritual Counterparts. Journeys of the Soul: Anthropological Studies of Death, Burial, and

Reburial Practices In Borneo, William D. Wilder, Editor. Borneo Research Council Monograph No. 7. Phillips, Maine: Borneo Research Council, Inc.

Heaven at the Edge of Borneo. Communications \& Publicity Division, Tourism Malaysia. 2 July 2012. 
Herman. (2000). The Rungus: The Art of Blending Traditional Life-Style into the 20th Century accessed on 27/02/2014 at www.flyingdusun.com.

Hutton, Wendy. (2003). Kudat. Natural History Publications: Kota Kinabalu.

Massey, A. et. al (2011). Beware the Animals that Dance: Conservation as an Unintended Outcome of Cultural Practices. Society, Biology and Human Affairs: Durham.

Ong, P. L. (2005). Rumah Panjang Tradisi Rungus dalam Arus Pembangunan: Perbezaan Pengertian. Akademika 68 (Januari) 2005: $43-64$.

PengiranBagul, A. H. B. (2005). (ed. Kaye Chon) Community-Based Ecotourism Development and Local Community Participation. One Earth One Family: Travel \& Tourism - Serving a Higher Purpose. 3rd Global Summit on Peace through Tourism - Education Forum. Pattaya, Thailand • October 2-5, 2005. p. 6.

Philips, M.E. (2008).The Longhouse of the Tarsier: Changing Landscapes, Gender and Well Being in Borneo. Borneo Research Council Monograph Series. Carol J. Pierce Colfer (ed.). 433 pp. Southeast Asia Program Publications: Cornell University.

Sokial, R. N. A Comparison between Traditional Longhouses in Sabah and Sarawak. The Sabah Architectural Heritage accessed on 27/02/2014 at www.sabahwarriors.blogspot.com.

\section{ACKNOWLEDGEMENT}

The authors would like to acknowledge the Universiti Sains Malaysia for funding this research under the Exploratory Research Grant Scheme (ERGS) 203/PPBGN/6730130 and the School of Housing, Building and Planning, Universiti Sains Malaysia for this research project. 